\title{
Repositioning the Old, Existing Copper-Binding Drugs for Cancer Treatment
}

\author{
Q. Ping Dou* \\ Departments of Oncology, Pharmacology and Pathology School of Medicine Wayne State University Detroit, Canada
}

The conventional approach toward anti-cancer drug development is expensive and time-consuming. One approach to expedite this process and achieve more affordable means is to discover new uses of old, existing drugs, since their pharmacokinetics and pharmacological profiles have been well established [1]. Recent studies reveal anti-cancer activities of several approved copper $(\mathrm{Cu})$-binding drugs including disulfiram (an anti-alcoholism drug), clioquinol (a drug for treatment of Alzheimer's and Huntington's diseases) and ditiocarb (or diethyldithiocarbamate, a drug for treatment of HIV-1 infection) [2,3]. In vitro and in vivo studies have discovered a new mechanism in which these old drugs target and react with tumor cellular copper, forming complexes that act as potent proteasome inhibitors and apoptosis inducers in human cancer cells [4]. Extensive studies have strongly supported the idea that $\mathrm{Cu}$ could be used as a novel, selective target for human cancer therapies. First, $\mathrm{Cu}$, but not other metals, is a co-factor essential for the processes of tumor angiogenesis [4,5]. Secondly, high tissue levels of $\mathrm{Cu}$ have been found in many types of human cancers, including breast, prostate, colon, lung and brain $[4,6,7]$. Thirdly, significant decrease in Cu levels in mammalian organs does not cause detectable side effects [8]. Finally, in clinical trials with patients suffering from metastatic cancers, use of the $\mathrm{Cu}$ chelator tetrathiomolybdate achieved the Cu-deficiency and stabilization of disease in a large portion of the patients, demonstrating the clinical feasibility [9]. It has been found that some organic $\mathrm{Cu}$ complexes can selectively inhibit the cancer cellular 26S proteasome activity, resulting in induction of apoptosis [10]. Furthermore, a Cubinding ligand alone can induce proteasome inhibition and apoptosis in $\mathrm{Cu}$-enriched human cancer cells that mimic in vivo situations of many human tumors $[4,10]$. Some of the $\mathrm{Cu}$ ligands tested include disulfiram, clioquinol and ditiocarb. All of them are able to interact with $\mathrm{Cu}$, forming complexes with potent proteasome-inhibitory and apoptosis-inducing abilities in tumor cells in vitro and in vivo [4]. This identified mechanism of action of these approved $\mathrm{Cu}$-binding drugs may be responsible for their observed anticancer activities.

The potential advantage for using these existing $\mathrm{Cu}$-binding drugs for cancer therapies is apparent. Due to the fact that $\mathrm{Cu}$ concentrations are elevated in cancer but not normal cells $[4,6,7]$, disulfiram, clioquinol and ditiocarb should have more selective effect against cancer and can bind the endogenous $\mathrm{Cu}$ in tumors to form a $\mathrm{Cu}$-based proteasome inhibitor. Due to the difference of $\mathrm{Cu}$ levels in tumor and normal tissues [4,6,7], it is possible that these compounds may have little or no toxicity to normal cells while maintaining their anticancer activity. The studies using old $\mathrm{Cu}$-binding drugs provided strong support for proofof-concept of converting the pro-angiogenic cofactor $\mathrm{Cu}$ in cancer cells to the anti-angiogenic proteasome inhibitor and a cancer cell death inducer [4]. Identification of the new mechanism of action of the approved $\mathrm{Cu}$-binding agents as potential proteasome inhibitors and anticancer drugs should have great significance in developing novel strategies for the treatment of human cancer. If successful, these old $\mathrm{Cu}-$ binding drugs could be immediately moved to anticancer clinical trials to determine their efficacy and toxicity. Since the drug development process can be burdensome replete with regulatory demands [1], the concept of repositioning of old drugs could represent a significant achievement in establishing positive momentum in generating further lead candidates in anticancer drug discovery.

\section{References}

1. Mullard A (2011) Could pharma open its drug freezers? Nat Rev Drug Discov 10: $399-400$.

2. Frezza M, Hindo S, Chen D, Davenport A, Schmitt S, et al. (2010) Novel metals and metal complexes as platforms for cancer therapy. Curr Pharm Des 16 : 1813-1825.

3. Ruiz-Azuara L, Bravo-Gómez ME (2010) Copper compounds in cancer chemotherapy. Curr Med Chem 17: 3606-3615.

4. Daniel KG, Chen D, Yan B, Dou QP (2007) Copper-binding compounds as proteasome inhibitors and apoptosis inducers in human cancer. Frontiers in Bioscience 12: 135-144.

5. McAuslan BR, Reilly W (1980) Endothelial cell phagokinesis in response to specific metal ions. Exp Cell Res 130: 147-157.

6. Rizk SL, Sky-Peck HH (1984) Comparison between concentrations of trace elements in normal and neoplastic human breast tissue. Cancer Res 44: 53905394.

7. Kuo HW, Chen SF, Wu CC, Chen DR, Lee JH (2002) Serum and tissue trace elements in patients with breast cancer in Taiwan. Biol Trace Elem Res 89: $1-11$.

8. Brewer GJ, Dick RD, Grover DK, LeClaire V, Tseng M, et al. (2000) Treatment of metastatic cancer with tetrathiomolybdate, an anticopper, antiangiogenic agent: Phase I study. Clin Cancer Res 6: 1-10.

9. Redman BG, Esper P, Pan Q, Dunn RL, Hussain HK, et al. (2003) Phase II trial of tetrathiomolybdate in patients with advanced kidney cancer. Clin Cancer Res 9: 1666-1672.

10. Daniel KG, Gupta P, Harbach RH, Guida WC, Dou QP (2004) Organic copper complexes as a new class of proteasome inhibitors and apoptosis inducers in human cancer cells. Biochem Pharmacol 67: 1139-1151.

*Corresponding author: Q. Ping Dou, Professor and Co-Leader Developmenta Therapeutics Program Barbara Ann Karmanos Cancer Institute Departments of Oncology, Pharmacology and Pathology School of Medicine, Wayne State University Detroit, Canada, Tel: 313-576-8301; Fax: 313-576-8307; E-mail: doup@karmanos.org

Received January 25, 2012; Accepted February 10, 2012; Published February 13, 2012

Citation: Dou QP (2012) Repositioning the Old, Existing Copper-Binding Drugs for Cancer Treatment. Clin Exp Pharmacol 2:e102. doi:10.4172/2161-1459.1000e102

Copyright: (c) 2012 Dou. This is an open-access article distributed under the terms of the Creative Commons Attribution License, which permits unrestricted use, distribution, and reproduction in any medium, provided the original author and source are credited. 